\title{
Mulemba
}

\section{Cheikh Anta Diop revisitado}

\author{
Almerindo Jaka Jamba
}

\section{OpenEdition}

\section{Journals}

\section{Edição electrónica}

URL: http://journals.openedition.org/mulemba/433

DOI: $10.4000 /$ mulemba.433

ISSN: 2520-0305

\section{Editora}

Edições Pedago

\section{Edição impressa}

Data de publição: 1 maio 2015

Paginação: 481-492

ISSN: 2182-6471

\section{Refêrencia eletrónica}

Almerindo Jaka Jamba, «Cheikh Anta Diop revisitado», Mulemba [Online], 5 (9) | 2015, posto online no dia 22 novembro 2016, consultado o 26 janeiro 2021. URL: http://journals.openedition.org/mulemba/ 433 ; DOI: https://doi.org/10.4000/mulemba.433

Este documento foi criado de forma automática no dia 26 janeiro 2021.

Tous droits réservés 


\title{
Cheikh Anta Diop revisitado
}

\author{
Almerindo Jaka Jamba
}

\section{NOTA DO AUTOR}

Texto da apresentação pública da tradução portuguesa da obra organizada por Babacar Mbaye Diop e Doudou Dieng, A consciência histórica africana (Tradução de Narrativa Traçada, revisão de Susana Ramos. Luanda, Edições Mulemba; Mangualde, Edições Pedago, 2014, 224p. [«Reler África»]), lido durante o «Ciclo de actividades em alusão ao Dia de África», no Anfiteatro principal da Faculdade de Ciências Sociais (FCS) da Universidade Agostinho Neto (UAN), em Luanda, em 25 de Maio de 2015.

1 A obra A consciência histórica africana, cuja organização se deve a Babacar Mbaye Diop e Doudou Dieng, é constituída por um conjunto de intervenções proferidas no colóquio que teve lugar na Universidade de Rouen em França, nos dias 5 e 6 de Abril de 2005, por ocasião da celebração do $50 .$. aniversário da publicação da obra de Cheikh Anta Diop, Nations nègres et culture. 0 livro, de 224 páginas, está organizado em quatro partes, nomeadamente um prefácio intitulado «Falsificação da história» (pp. 19-21), da autoria dos organizadores e três capítulos com os títulos seguintes: «A África $e$ o Ocidente» (Capítulo I, pp. 23-83); «As raízes egípcias da civilização africana» (Capítulo II, pp. 85-164), e «O contributo da comunidade negra e do Egipto para a civilização» (Capítulo III, pp. 165-214). Inclui ainda o «Discurso de abertura» do colóquio (pp. 15-16), pelo Presidente da A.S.E.R., Samba Kandji e, no fim da obra, os «resumos» das conferências (pp. 215-220).

Em relação ao Capítulo I, o primeiro prelector foi o historiador senegalês Bwemba Bong, com a comunicação intitulada «A ruptura da consciência histórica do povo negro: o obstáculo principal do renascimento africano» (pp. 25-45). Para Bwemba, a consciência histórica desempenha um papel importante na libertação e elevação mental de um povo, que toma consciência do seu passado. As relações entre a África e o Ocidente conheceram ao longo da história vários acidentes, tais como o tráfico de escravos, a colonização, os traumatismos políticos, económicos, culturais e psicológicos, que tornaram o povo africano amnésico. A memória histórica colectiva foi profundamente atingida. $\mathrm{O}$ 
Ocidente, para tentar legitimar a dominação política, económica e cultural dos povos da África recorreu à ideologia da mistificação e da falsificação do passado dos povos africanos, procurando sempre apresentar a África como um continente «sem história». Contudo, para Bwemba, a era do continente africano «sem história» terminou desde a publicação em 1954, de Nations nègres et culture. Cheikh Anta Diop ao recusar a visão hegeliana da história humana dedicou-se ao restabelecimento da consciência histórica africana.

Bwemba, na mesma senda de Cheikh Anta Diop, sustenta que a civilização primeira conhecida da humanidade teve como berço o vale do Nilo, e que foi através duma falsificação histórica, que os ocidentais classificaram o Egipto no Oriente. 0 Egipto não é o Oriente, o Egipto é a África. Por conseguinte, a África deve orgulhar-se dos vestígios da antiguidade africana, assim como da bela época dos seus grandes impérios dos séculos $\mathrm{X}$ ao $\mathrm{XV}$, dos seus reinos e de demais unidades políticas, mas também deve estudar as fragilidades e os defeitos da sociedade africana. Por último o autor recomenda que a África Negra deve extrair da história as lições que contribuíram para o seu enfraquecimento, tanto as causas internas como as causas externas.

Um outro ângulo de abordagem da relação entre «África e o Ocidente» no Colóquio de Rouen, foi a dimensão mediática, mais concretamente da projecção da guerra do Biafra pela imprensa escrita francesa. A segunda comunicação, denominada justamente, «A guerra do Biafra: desinformação e manipulação dos média? Análise de quatro grandes diários: Le Monde, Le Figaro, La Croix e L'Humanité» (pp. 47-58), e inscrita ainda no capítulo em análise, deve-se a um outro historiador, Momar Mbaye. Segundo este prelector, a guerra do Biafra foi um conflito que ensaguentou a Nigéria de 1967 a 1970 e que provocou mais de dois milhões de mortos. Foi um acontecimento que provocou a indignação da opinião pública e a mobilização dos média a nivel mundial. Certas publicações, que se debruçaram sobre as relações da imprensa francesa com a terrível guerra do Biafra, insinuavam uma eventual desinformação e manipulação dos média franceses através de agentes pro-biafrenses.

5 Para se clarificar esta suposição Momar Mbaye analisou o tratamento da guerra do Biafra em termos de causas passadas e imediatas, causas estratégicas e económicas, causas religiosas e responsabilidades em quatro periódicos franceses de tendência e obediência diversa. Longe de consagrar a ideia duma cobertura mediática distorcida e tendenciosa, o prelector sustenta a ideia de que a situação é mais complexa de abordar. Relativamente a uma eventual manipulação da imprensa francesa por agentes probiafrenses, Momar Mbeye sustenta que os quatro periódicos mantiveram mais ou menos a sua linha editorial tradicional e que os artigos foram pouco críticos em relação aos secessionistas.

6 No quadro da relação entre a África e Ocidente, durante o Colóquio de Rouen, uma atenção especial foi dedicada à problemática decorrente da colonização linguística, tendo como caso de estudo a França e as suas ex-colónias, isto é do binómio Francês/ Línguas Africanas. Assim, para tal, o linguista Bernard Zongo apresentou a comunicação denominada «Francês/Línguas africanas: colonização linguística, ontem e hoje, aqui e ali» (pp. 59-83). Para este linguista, as relações francês/línguas africanas, têm sido caracterizadas ao longo da história por uma hegemonia, uma imposição da língua françesa em detrimento daquilo que, numa primeira fase, foi designado de «dialectos, patoás» e mais tarde por força de circunstâncias de «línguas africanas». Na abordagem desta problemática glotofágica, Zongo distingue quatro grandes períodos assim 
dispostos: período colonial, período moderno, período da sociolinguística, período do surgimento das instituições francófonas. Vejamos, em poucas palavras, a caracterização particular que ele faz dos mesmos:

7 a) Período colonial: é o período da chegada às colónias, também designado de linguística pragmática e caracteriza-se pela preocupação dos primeiros africanistas, viajantes, administradores, etnólogos, linguistas, em repertoriarem as populações que habitavam os territórios que atravessavam, assim como as línguas que falavam. A intenção subjacente a esses escrevedores resumia-se na fórmula «poder comunicar para melhor dominar», isto para os administradores e para os missionários, «poder comunicar para melhor evangelizar». De salientar que esses escrevedores eram investigadores de circunstância e as suas descrições não buscavam valorizar ou proteger as línguas africanas;

8 b) Período moderno: este período, que surge depois da segunda guerra mundial (1945), é também chamado do triunfo do formalismo e da missão civilizadora. É a época em que os investigadores são linguistas confirmados, que procedem à recolha sistemática de materiais (IFAN, 1938-1965). Apesar desses avanços, e sobretudo, com a elaboração de inventários das quatro grandes famílias descritas pelo linguista norte-americano Joseph Greenberg, a preocupação dos africanistas franceses estavam mais relacionadas com a ideologia da dominação colonial em detrimento da preservação ou valorização das línguas africanas;

9 c) Período da sociolinguística: como bem sublinha Bernard Zongo, no plano científico, os anos sessenta foram marcados pela fragilização do formalismo, bem como pela emergência da linguística contrastiva favorecida pelo desenvolvimento da psicolinguística e da necessidade de uma melhor implementação do francês face às línguas africanas, consideradas a partir de então como obstáculos à aprendizagem do francês. Foi a partir de então que foram criados Centros de linguística aplicada. Tratava-se, assim, de levar a cabo «análises contrastivas» ao serviço da necessidade de se corrigir «os erros» através da especificação das dificuldades encontradas pelo locutor de língua diferente em situação de aprendizagem;

10 d) Período da criação de instituições da francofonia: A criação das instituições francófonas, constituiu um elemento de frustração para os africanos, porque longe de corresponder a «um lugar para dar e receber» segundo o grande sonho de Léopold Sedar Senghor. A francofonia carregava também os germes da sua ambição dominadora e glotofágica. De salientar que mesmo a nível daqueles então designados como pais fundadores (Bourguiba, Diori, e sobretudo Senghor, optarão a ideologia do francês como «língua universal» ou como língua do «pensamento lógico».

11 Em conclusão, para o linguista Bernard Zongo, as relações entre o francês e as línguas africanas foram dominadas por uma estratégia glotofágica, de impor a língua francesa em detrimento das outras, desde o período colonial até ao período da criação de instituições francófonas.

12 Enfim, foram estas as quatro prelecções apresentadas durante o colóquio e que compõem a primeira parte da obra e foram estas as ideias e o espírito saído do colóquio, que determinaram a forma como esta primeira parte ficou assim delineada.

13 Como se disse no início, o segundo tema do colóquio tratou das «Origens egípcias da civilização africana», e a primeira comunicação intitulada «Cheikh Anta Diop: o homem e a obra» (pp. 87--110), foi orientada pelo filósofo e historiador Cheikh M’Baké Diop, co- 
editor da Ankh - Revista de Egiptologia e das Civilizações Africanas. Trata-se, efectivamente, de um estudo bastante esclarecedor sobre o contexto histórico e ideológico do início do século $\mathrm{XX}$, assim como sobre as principais temáticas desenvolvidas por Cheikh Anta Diop. Quanto à contextualização histórica, o início do século XX é caracterizado pelo fim do sistema transatlântico do comércio dos negros e pela dominação militar, política, económica, cultural e psicológica de África, após a partilha e a ocupação do continente, que se seguiu depois da Conferência de Berlim (1884-1885). Ideologicamente, prevalecia a visão do Egipto Antigo, onde floresceu uma brilhante civilização da antiguidade, que é relacionado geográfica, antropológica e culturalmente à Asia Ocidental e ao mundo mediterrânico. É face a essa ideologia racista, à visão da África sem história e à falsificação da história, que Anta Diop empreende as suas investigações tendo em vista a reconstituição científica do passado da África e a restauração da consciência histórica africana.

o prelector identifica na obra de Cheikh Anta Diop, quatro grandes categorias temáticas, a saber:

a) A origem do homem e as suas migrações;

b) O parentesco Egipto Antigo/África Negra com argumentos de ordem cultural, sociológica, antropológica e histórica;

c) A investigação acerca das sociedades;

d) O contributo da África para a civilização.

19 A segunda comunicação, intitulada «O estado das investigações acerca das semelhanças entre a arte egípcia antiga e a da África negra» (pp. 111-124), colocada ainda no âmbito deste mesmo temário, deve-se ao historiador e egiptólogo Babacar Mbaye Diop.

Segundo este especialista, a diversidade e a profundidade das semelhanças entre a arte egípcia e a arte africana têm sido objecto de estudos da parte de conceituados investigadores. Sobre esta problemática bastante recorrente e que também foi levantada por Anta Diop em Nations nègres et culture, Babacar Diop questiona se a semelhança entre a arte africana e a arte egípcia é identitária ou analogia? Geograficamente, o Egipto faz parte da África, mas o seu legado artístico tem sido associado ao mundo cultural do Oriente Médio. Quanto às semelhanças entre a arte africana e a arte egípcia, Babacar Diop apresentou uma série de exemplos de semelhança entre objectos africanos e objectos egípcios dos quais se destacam os seguintes: a arte das tranças, a touca egípcia que se encontra em qualquer parte da África, a cabeceira egípcia e o apoio de cabeça africano, o $\mathrm{mr}$ dos Egípcios e a enxada dos africanos, os bastões, maças e ceptros do Egipto e da África Negra, a forma arquitectural dos monumentos, e os instrumentos de música tais como as harpas. Babacar Diop conclui o seu estudo dizendo que a relação entre a arte africana e a arte egípcia não é uma relação de analogia e que as semelhanças entre vários objectos não podem ser consequência de um mero acaso.

21 Ainda no âmbito deste mesmo temário se inscreve a terceira comunicação, da autoria de Babacar Sall, intitulada «Estado das investigações acerca da antiguidade africana» (pp. 125-141), que nos diz que o estudo da História da Antiguidade Africana foi um dos objectivos que levaram Anta Diop a escrever Nations Nègres et Culture para permitir a qualquer africano poder remontar a história da África, desde os tempos mais longíguos. Cheikh Anta Diop, apoiando-se nas investigações que tinham sido efectuadas, havia chegado às conclusões de que a África teria sido o continente: 

fontes textuais, quer de fontes arqueológicas. Das fontes textuais cabe-nos destacar os textos gregos antigos. O Vale do Nilo representa o local melhor estudado porque apresenta o maior número de vestígios. Sobre as outras regiões a arqueologia permitiu a obtenção de informações acerca do povoamento e dos géneros de vida. Como bem sublinha Babacar Sall na sua comunicação «Cheikh Anta Diop é, de modo praticamente incontestável, o fundador da Escola africana de História, não somente da história das sociedades africanas, mas pura e simplesmente da história».

A quarta comunicação, enquadrada ainda no grande tema sobre «As origens egípcias da civilização africana», foi apresentada pelo professor de história e egiptólogo da Universidade Cheikh Anta Diop de Dakar (Senegal), Moussa Lam e tem por título «Egipto antigo e África Negra: Alguns factores novos que esclarecem as suas relações» (pp. 143-157).

Os grandes questionamentos à volta dos quais gravita a comunicação deste especialista senegalês são os seguintes:

- A civilização do Egipto Antigo esteve isolada da civilização da África Negra ou existiu uma profunda unidade cultural e racial entre o Egipto Antigo e a África Negra?

Terá existido uma unidade Egipto-Africana, cujo berço terá sido o Egipto Antigo e que com o enfraquecimento e a queda do poder faraónico ter-se-á deslocado por vagas migratórias sucessivas em direcção ao interior do continente?

Serão os antigos egípcios invasores provenientes do exterior da África (tese do pai da Egiptologia Gaston Maspero 1846-1916) ou terão sido, segundo Claire Lalouette, mestiços de africanos e de semitas vindos da Ásia a partir do quarto milénio?

Estas são as grandes interrogações que se levantam à volta das relações Egipto antigo e África Negra e levaram à emergência de duas escolas de egiptologia: a escola egiptológica ocidental, que prima pelo isolamento do Egipto antigo e da África Negra, e a escola egiptológica africana que, na senda da perspectiva indicada por Cheikh Anta Diop, defende a existência duma profunda unidade cultural e racial Egipto-Africana.

o professor Moussa Lam, na sua comunicação apresenta o que ele considera como descobertas pessoais, no domínio da linguística. Partindo de um léxico comparado entre o Egipto antigo e as línguas negro-africanas do oeste da África, nomeadamente o fula (essencialmente), wolof, serere, soninqué, bambara, dogon; o ilustre egiptólogo constata similitudes que confirmam inteiramente a unidade cultural perspectivada e defendida por Cheikh Anta Diop. Partindo de amostras de termos relativos às partes do corpo, à agua, à agricultura, ao anão, ao pigmeu, ao hipopótamo e ao cavalo, Moussa Lam afirma ter contribuído a partir da linguística para a confirmação da profunda unidade cultural que se forjou e se fortificou no Vale do Nilo.

33 A quinta e última comunicação do segundo tema teve como prelector Doudou Dieng e tratou da "“Afrocentricidade": polémica em torno de um conceito» (pp. 159-164). A comunicação deste especialista sobre a "afrocentricidade» é uma abordagem que visa reposicionar a história do pensamento e da filosofia africana na nova perspectiva proposta por Cheikh Anta Diop, do regresso às origens para melhor tornar inteligível o 
pensamento africano, incluindo a África no seu todo. Esta maneira de encarar o pensamento filosófico africano está nas antípodas duma certa tradição, que buscava contar a história da filosofia africana iniciando com o filósofo africano Guilhaume Amo ou com a filosofia bantu do missionário Belga Placide Tempels. Por conseguinte, o egiptólogo Theóphile Obenga, na sua introdução à La Philosophie Africaine de la période pharaonique, contrariamente à periodização anterior, propôs quatro períodos da história da filosofia africana, concomitantes com a história geral do continente a saber:

1) o período egípcio faraónico desde o antigo Império, com os textos das pirâmides, 2780-2260 a.C.;

2) Os filósofos e pensadores da Alexandria, de Cirene, de Cartago e de Hipona (seis séculos durante os quais a escola desempenha uma função importante no desenvolvimento do pensamento grego);

3) A filosofia magrebina com Ibn Badjadja, autor do tratado da alma, Ibn Battuta, o geógrafo, Ibn Khaldun, historiador e filósofo;

4) As escolas filosóficas medievais de Tombuctu, Gao, Djenné, berço da cultura negromuçulmana no tempo dos grandes impérios sudaneses (Gao, Mali, Songhai);

5) A filosofia africana moderna e contemporânea, representada por várias correntes de pensamento, e no que concerne à reflexão sobre a afrocentricidade, é importante ter em conta as fontes, os textos, e sobretudo, a tradição do pensamento africano.

Eis aqui, em resumo, o que se pode dizer acerca do conteúdo da segunda parte da obra.

40 A questão da contribuição da África Negra para o domínio das ciências e das técnicas constituiu também um dos sub-temas abordados no Colóquio de Rouen, constituindo precisamente a terceira parte: «O contributo da comunidade negra e do Egipto para a civilização», que compõe a obra em análise, começando por destacar o texto do primeiro prelector, Jean-Paul Mbelek, que fala do «Contributo da comunidade negra e do Egipto para a civilização» (pp. 167-183).

41 Jean-Paul Mbelek começou por recordar o apelo de Cheikh Anta Diop que na obra Les fondements économiques et culturels d'un État Fédéral d'Afrique Noire, convida os africanos a aprofundar o conhecimento das sociedades africanas sob todos os aspectos, a fim de se alcançar conclusões justas e pertinentes. No quadro da longa tradição inventiva no continente berço da humanidade, Mbelek sustenta que a tradição inventiva africana remonta à mais alta pré-história e à antiguidade e das grandes invenções podemos destacar a invenção do pensamento simbólico, há 80.000 anos (os artefactos da gruta de Blombos testemunham esta antiguidade), a invenção dos números há 37.000 anos (ossos de Lebombo) e a invenção da matemática há 37.000 anos (ossos de Ishango). A África também foi o berço da escrita. A escrita é uma invenção africana, e desde a publicação dos resultados das escavações efectuadas no túmulo do rei Escorpião chegou-se à conclusão que a cerca de seis mil e quatrocentos anos a escrita hieroglífica já estava constituída e os Egípcios utilizavam-na com as mesmas regras e os mesmos valores de ideograma, de fonograma ou de determinativo. De facto entre a invenção dos hieróglifos para o hieráctico (hieróglifos simplificados utilizados para os textos matemáticos em papiro) decorreram cerca de mil anos. Outros mil anos terão decorrido da passagem do hierático para o demótico (escrita cursiva).

42 A segunda comunicação do terceiro tema teve por prelector Cheikh Moctar Bâ, que tratou do "Contributo das cosmogonias Dogon para a problemática da "origem" da civilização: a necessidade do trágico no seio da divindade» (pp. 185-193). A explicação que a cosmogonia 
Dogon dá sobre a emergência trágica da civilização, foi também um dos sub-temas apresentados no Colóquio de Rouen. Segundo a tradição Dogon, o Deus criador Amma criou quatro gémeos: o Nommo die (Grande Nommo, com assento junto de Amma), o Nommo titiyane (segundo Nommo, mensageiro ou adjunto do primeiro), o Nommo (Nommo do lago que descerá à terra) e o Nommo anagonno ou Ogo (Quarto Nomo). De acordo com a tradição, estes Nommo eram constituídos por um princípio masculino. Amma o Deus criador tomou a decisão de criar gémeas, a fim de favorecer a multiplicação dos seres. Depois de ter gerado e apresentado as gémeas aos três primeiros, Amma passou a dedicar-se à criação da futura gémea de Ogo. Ogo receando não vir ver a sua gémea, revolta-se contra o criador e perturba toda a obra de Amma e daí o advento do trágico, querela e separação no seio da divindade. A emergência trágica da civilização inscreve-se no processo geral da existência e a civilização seria o resultado duma luta no seio da divindade, o culminar da rebelião de Ogo.

o Colóquio de Rouen teve como última comunicação a intervenção do Professor e egiptólogo congolês Théophile Obenga intitulada «O Egipto na obra de Platão» (pp. 195-214). Tratou-se da terceira comunicação do Capítulo III. A abordagem deste subtema, situa-se em duas vertentes: Dum lado, demonstrar a influência que o Egipto Antigo exerceu na emergência da filosofia e das ciências na Grécia e do outro lado, indagar o que é que representa o Egipto para Platão.

No que diz respeito à influência que o Egipto exerceu no plano da filosofia e das ciências (geometria e astronomia), importa referir as viagens de estudos dos gregos ao Egipto.

1) Tales de Mileto, o fundador da escola jónia estudou no Egipto;

2) Sólon de Atenas, o legislador ateniense também estudou em Saís, no Egipto;

3) Pitágoras de Samos, o fundador da Escola de Samos estudou igualmente no Egipto;

4) Xenófanes de Cólofon, fundador da Escola de Eleia, estudou no Egipto;

5) Anaxágoras de Clazómenas também visitou o Egipto, na esperança de aprender a teologia e uma ciência da natureza mais exacta;

6) Platão também estudou no Egipto, em Heliópolis, junto de um sacerdote egípcio Sekhnupis. Em 387 a.C. Platão regressa a Atenas e funda a Academia, escola filosófica que durou do século IV ao século I antes da nossa era.

51 Quanto à questão do que representa o Egipto para Platão, lendo atentamente os textos podemos chegar às seguintes conclusões:

52 a) O Egipto na obra platónica é tido como a terra da mais longa duração, e como lugar eleito da memória mais arquivada do mundo;

b) 0 Egipto é o berço da escrita e das ciências;

c) O Egipto é o modelo de organização artística e intelectual, que soube legislar com eficiência a questão educativa, a formação ética e cultural da juventude;

d) O Egipto como detentor da melhor pedagogia para ensinar as matemáticas às crianças.

Concluindo, podemos afirmar que tal como constata o Professor Obenga, o Egipto desempenhou um papel significativo no pensamento de Platão: perto de $42 \%$ dos seus discursos concernem directa e amplamente ao Egipto, país da mais alta antiguidade, berço da escrita e das ciências, modelo de organização artística e pedagógica. 
57 Finalmente, acerca da contribuição do investigador, historiador e egiptólogo Cheikh Anta Diop podemos parafrasear, Meinrad Hegba no seu artigo «L'homme vit aussi de fierté» que observou judiciosamente:

«[...] quando Cheikh Anta Diop, homem duma erudição enciclopédica, publicou a sua famosa obra Nations Négres et Culture, este foi atacado por todos os lados, ridicularizado, vilipendiado, porque a sua visão da história ousava desafiar o esquema dogmático traçado, entre outros por Hegel e Gobineau e que torna o homem negro aquele que nunca contribuiu para o património da humanidade».

Cinquenta anos depois e está o Colóquio de Rouen a comprová-lo, os temas desenvolvidos neste livro são actualmente discutidos como verdades científicas. Como bem pontuam os coordenadores da obra no prefácio do livro em toda a humildade de genuína atitude científica, citamos,

«Não se trata aqui de nos prostrarmos perante a obra de Cheikh Anta Diop, tal como aconteceria com um livro de orações. Temos plena consciência de que nem tudo é uniforme nos seus trabalhos: existem certamente aspectos, que não conseguiu desenvolver até ao fim. Pretendemos apenas homenagear o homem da ciência, celebrar a sua produção intelectual, permanecendo fiel ao seu pensamento».

Depois da apresentação dos temas e subtemas da obra A consciência histórica africana, assim como a indicação dos respectivos prelectores, cabe-nos saudar a tradução desta importante obra para a língua portuguesa. É que, obras de grande actualidade e pertinência como esta, há muito que já deveriam estar acessíveis para o grande público na língua que os utentes melhor a dominam.

\section{AUTOR}

\section{ALMERINDO JAKA JAMBA}

jakajamba@gmail.com

Professor Auxiliar do Departamento de Sociologia (DS) da Faculdade de Ciências Sociais (FCS) da Universidade Agostinho Neto (UAN).

Licenciado em Filosofia (1972), pela Universidade Clássica de Lisboa (Portugal); Mestre em Relações Internacionais e Estudos Superiores Diplomáticos (2007), pelo Centro de Estudos Diplomáticos e Estratégicos do Instituto de Altos Estudos Internacionais; pós-graduação em Filosofia (1974) pela Faculdade de Letras da Universidade de Genebra (Suiça) e em Resolução de conflitos (1998) pela Universidade de Uppsala (Suécia); Curso de Língua e Civilização Francesa pela Faculdade de Letras da Universidade de Genebra (Suiça) e Curso de Língua Inglesa pela Universidade de Paris (França). É Professor Auxiliar do Departamento de Sociologia da Faculdade de Ciências Sociais (FCS) da Universidade Agostinho Neto (UAN), onde ensina as disciplinas de Fundamentos de Filosofia e Lógica. É professor de Diplomacia e Negociação Internacional, Integração económica e História contemporânea de Angola no Instituto Superior de Ciências Sociais e Relações Internacionais (CIS). As suas áreas de interesse são: História da Filosofia, Filosofia Africana, Antropologia Cultural e Diplomacia e Negociação Internacional. Materiais publicados: Chine/États Unis d'Amérique: confrontation ou coopération? Paris, Centre d'Études Diplomatiques et Stratégiques de Paris, 2007 [Trabalho de fim do curso]; Building Nation in plural 
societies, Uppsala University, 1998 [Trabalho de fim do curso apresentado no Departamento de Paz e Investigação de Conflitos, Reino da Suécia]; Le divertissement chez Pascal. Genebra, Faculté de Lettres, Université de Genebra, 1974 [Trabalho de pós-graduação]. Anteriormente, desempenhou as seguintes funções: Secretário de Estado da Informação do Governo de Transição de Angola (1975), Deputado (1997-2004), Vice-Presidente da Assembleia Nacional (2008-2012) e Embaixador (Representante Permanente) da República de Angola junto da UNESCO (2004-2008). 